
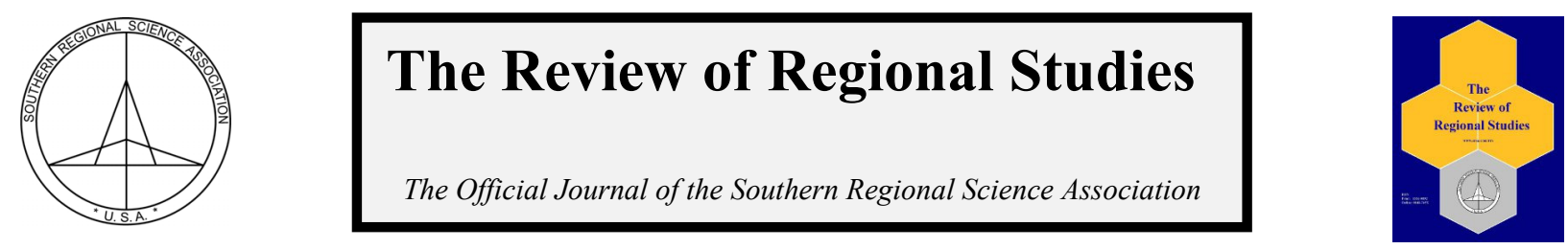

Fellows Address-Mobile, Alabama, March 27, 2015

$54^{\text {th }}$ Meetings of the Southern Regional Science Association:

\title{
Are Industry Clusters and Diversity Strange Bedfellows?
}

\author{
Randall Jackson
}

Regional Research Institute, West Virginia University, USA

\begin{abstract}
In this address, I review industry clustering and diversification strategies to compare and contrast their underlying foundations. The lack of a consensus choice of one or the other for regional economic development strategies along with the recognition that in the dynamic process of development these two processes are related leads me to conclude that clusters and diversity need not be such strange bedfellows after all, and that a rational approach to economic development can leverage the strengths of each and offset weaknesses. I follow this discussion by introducing a cluster assessment diversification strategy (CADS) apparatus that can be used to measure existing cluster strength, identify industrial strengths and deficit bottlenecks, and explore the regional consequences of potential cluster diversification strategies.
\end{abstract}

Keywords: industry clusters, industry diversification

JEL Codes: R00, R12, R58

\section{INTRODUCTION}

The relationship between economic structure and economic performance has permeated regional science research from its very inception. From work developing Perroux's growth poles and economic spaces through Isardian industrial complexes and clusters to the views of Marshall and Jacobs on agglomeration concepts and economic diversity, the stage was set early for lively and continued debate over the nature of regional economic development, the dynamics of regional industrial structure, and regional growth and stability. For evidence of the unfaltering interest in this relationship, we need look no further than the three most recent Southern Regional Science Association (SRSA) conference programs in which, by my count, there were 11 papers with either industry clustering or diversification in their titles. In preparing for this address, I was able to identify fairly easily more than 80 similarly titled journal articles and a few dozen more related book chapters since 2000. The centrality of the topic to regional science is as clear as is the fact that an understanding of the relationships among economic structure and performance is elusive and incomplete.

For me these topics hold special interest because An Evaluation of Alternative Measures of Regional Industrial Diversity (Jackson, 1984) was my first regional science related publication, and many of my publications in the 30 years since those early days have explored different aspects of regional economic structure, structural change, and economic performance.

Jackson is Director or the Regional Research Institute and Professor of Geology and Geography at West Virginia University, Morgantown, WV 26506. E-mail: Randall.Jackson@mail.wvu.edu

(c) Southern Regional Science Association 2015.

ISSN 1553-0892, 0048-749X (online)

www.srsa.org/rrs 
My interests developed from a thorough grounding in industrial location theory and an early realization that public sector regional economic development strategies were essentially the flip side of the coin from private sector application of location theory and location analysis.

Of course, this realization also brings with it the question of whether any kind of development strategies focusing on specific industries is well advised, since private sector decisions are driven by location factors and also generally result in efficient allocations of factors of production. Mark Partridge, in his 2006 Presidential Address (Partridge, 2006), in Partridge and Olfert (2010) and again in his 2013 SRSA Fellows address (Partridge, 2014), cautioned strongly against picking winners as an approach to development. Likewise, Doug Woodward's 2013 Presidential Address also urged "caution regarding development incentives as a regional strategy ..." suggesting "that stronger agglomeration and cluster-based strategies are better suited to promote contemporary economic development," and the literature is rife with other cautionary notes, including Neffke, Henning, and Boschma (2011, p. 261) whose empirical evidence suggests that "self-selection of industries into regions that host a substantial amount of related economic activities suggests there may be only limited justification for targeted industrial policy." The general recognition of a need for caution, however, has not seemed to dampen enthusiasm for research probing the fundamental relationships that link regional economic structure and performance, relationships that lie at the heart of our understanding of regional economic systems and system dynamics.

Among the more striking developments of the last quarter century, of course, is the position of relative dominance to which industrial clustering approaches to regional development have risen. "Industry clusters have generated an extraordinary amount of interest in contemporary debates on regional economic development theory and praxis across a wide range of academic disciplines and policy circles" (Bekele and Jackson, 2006, p. 2). Emphasizing clusters dominance over diversity, Desrochers and Sautet (2008, p. 826) add that,

In the wake of the success of Michael Porter's cluster strategy and a long-held belief that the geographical specialization of economic activities is a desirable outcome of trade and the division of labor, regional development policy in the last two decades has heavily favored regional specialization at the expense of local economic diversity.

According to Stough (2015, p. 223) "The cluster concept is well known and often the basis for contemporary policy and practice in economic development." Woodward (2013, p. 1) adds "... cluster initiatives form the basis for much of regional policy around the world." In his view (p. 18) "the cluster approach is at the forefront of regional policy...(and)...has become an instrument included in state and local economic development toolboxes." Despite numerous critiques of various clustering constructs, (see Martin and Sunley 2003; Yu and Jackson, 2011) "...the allure of cluster-based approaches to economic development policy remains strong" (Spencer et al., 2010, p. 712).

Others have observed both the tensions that exist between clustering and diversity, and the relationships among them. Desrochers and Sautet (2008, p. 814) for example, concluded "that the regional setting most conducive to entrepreneurial activity is probably a diversified city made up of many specialized clusters, which is what most thriving cities have historically spontaneously evolved into." Indeed, according to Malizia and Feser (1999, p. 92), contrary to the view that diversity is defined by the absence of specialization, "economic diversity is the presence of multiple specializations." 
My intent is to provide a bit of historical perspective, discuss cluster approaches and diversification strategies and measurement, and consider whether the two apparently competing forces might find ways to peacefully co-exist. A comprehensive review would fill volumes, and I will undoubtedly neglect many important contributions. Still, I believe my remarks will identify a representative cross-section of current thought. In the final canto of this address, I will present a measurement tool that I believe can be used to identify the normative structure of a cluster as a reference for measuring cluster strength and as the foundation for assessing the implications of the additions of new specializations as regions grow and diversify.

\section{ECONOMIC STRUCTURE}

\subsection{Notable Precursors}

The growth pole/growth center literature that built upon Perroux's (1950) seminal contributions was among the earliest theoretical frameworks addressing industrial structure and helped usher in cluster development approaches. The two related, but less than identical, constructs laid the groundwork for substantial conceptual development over the first quarter century of regional science research (see Hansen, 1967; Darwent, 1969; Lasuen, 1969; Campbell, 1972; Parr, 1973; Beyers, 1974; Thomas, 1975). It also fueled a parallel effort focusing on the identification of key sectors, those propulsive growth pole industries whose activities stimulate greater than average activity among industries in an economic system (early examples include Rasmussen, 1957; Hirschman, 1958; and Chenery and Watanabe, 1958).

A second and often undervalued contribution to more sophisticated structural economic analysis methods is economic base theory (see Andrews 1953a, 1953b, 1955; Blumenfeld, 1955; Mattila and Thompson, 1955; Leven, 1956; Tiebout, 1956; Ullman and Dacey, 1960). The lack of regard for economic base theory and analysis might be due to its simplicity and the rise in popularity of more sophisticated and more highly disaggregated models of regional systems, but vestiges of its emphasis on the distinction between basic industries satisfying exogenous demand and those industries that support them can be seen in nearly all modern economic systems models.

\subsection{Clusters}

During its early decades, regional science scholars also began developing theories and methods for identifying and analyzing industrial cluster and complex concepts explicitly (Isard and Vietorisz, 1955; Isard and Schooler, 1959; Streit, 1969; Ghosh and Chakravarti, 1970; Czamanski, 1971, 1973, 1977; Roepke, Adams, and Wiseman, 1974; Czamanski and Czamanski, 1977; Czamanski and Ablas, 1979; Norcliffe and Kotseff, 1980; Loviscek, 1982; O'hUallachain, 1984). Most of these studies were input-output (I-O) based and firmly established interindustry linkages and input output frameworks as essential tools for studies of economic structure. ${ }^{1}$

Substantial numbers of earlier contributions notwithstanding, few would dispute that the cluster approach to development really hit its stride at the confluence of Porter's contributions (1990, 1996, 2000, 2003) and Krugman's (1991, 1998) papers on the agglomeration and the "new economic geography." From the 1990s onward, clusters have carved out a clear position of prominence - if not pre-eminence_-in the regional economic development domain. "While the

\footnotetext{
${ }^{1}$ Though not focused directly on clustering, work building on Chenery and Watanabe (1958) focused on I-O based economic system structural comparisons.
}

(C) Southern Regional Science Association 2015. 
cluster strategy has been criticized on several counts,..., it has nonetheless successfully overturned the previously prevalent diversification objective of most local development officials and established regional specialization as the preferred goal (Rosenfeld, 2001)" (Desrochers and Sautet, 2008, p. 813).

Although a consensus cluster definition has been somewhat elusive, there are commonalities across the cluster literature, and researchers seem to "know them when they see them." The following characteristics appear often:

- Sectoral specialization and comparative advantage,

- Interindustry interdependencies in buyer-supplier relationships,

- Co-location among related cluster industries leading to denser interindustry linkages and lower transaction costs,

- Industry-specific knowledge spillovers from more intense interactions, and

- Productivity gains from specialization and labor market pooling.

Despite a lack of clear consensus, Rocha and Stenberg (2005, p.270) conclude that "clusters have three necessary or defining dimensions: geographical proximity, an inter-firm network, and an inter-organizational or institutional network."

\subsection{Cluster measurement}

We should acknowledge at the outset that cluster measurement based solely on secondary data will almost surely fall short of identifying anything more than the potential for the kinds of dialogue and communications networking that Deller (2012) identifies as part of the definition of clusters. "A common weakness of most of the existing approaches is that they do not incorporate collaboration among cluster participants" (Reid, Smith, and Carroll, 2008, p 346). Rocha and Sternberg $(2005$, p. 268) define agglomerations as "clusters without networks." The suggestion is that agglomerations are necessary but not sufficient conditions for clusters. In this sense, cluster measures based on secondary data alone might more appropriately be called agglomeration measures, but to maintain consistency with the literature, we will continue to use cluster measure in this exposition. ${ }^{2}$

Dozens of methods have been proposed for identifying clusters (Bekele, 2007). The industry complex and cluster literature listed earlier identifies a large number of mostly I-O based candidate measures. Kelton Pasquale, and Rebelein (2008, p. 307) used a common approach to identifying NAICS clusters following the Feser and Bergman (2000) cluster stipulations that "for two industries, A and B, to be considered part of the same cluster, they must be linked in one of the following four ways:

- A buys directly or indirectly from B;

- A sells directly or indirectly to B;

- $\mathrm{A}$ and B have similar purchase patterns from other industries; or

- $\quad \mathrm{A}$ and B have similar sales patterns to other industries.

Both Kelton Pasquale, and Rebelein (2008) and Feser and Bergman (2000) identify clusters using these dimensions by applying correlation analyses to national input-output data. More recent contributions to the cluster measurement literature are Titze, Brachert, and Kubis

${ }^{2}$ See Parr (2002) for a comprehensive review and clarification of agglomeration concepts.

(C) Southern Regional Science Association 2015. 
(2011) use of qualitative I-O to identify clusters (MFA - minimal flow analysis) and Deller's (2012) approach to filling the industrial gaps in regional industrial structure using I-O methods as a foundation.

Delgado et al. (2014) have recently published an NBER report that provides extensive detail on the Harvard cluster mapping program methodologies. According to their website, "Strong clusters are defined as those where the location quotient, i.e. the cluster's relative employment specialization, puts them into the leading $25 \%$ of regions across the U.S. in their respective cluster category." ${ }^{3}$ The characteristics of location quotients (LQs) are well known, of course, with LQ values exceeding 1.0 indicating that an industry's concentration in the study region is greater than its concentration in the reference region. ${ }^{4}$

There is an interesting parallel between the LQ and Balassa's (1965) Index of Revealed Comparative Advantage (RCA), which is better known to the international trade community than it is to regional scientists. The RCA is based on export proportions rather than employment proportions: But like the RCA, LQs reveal concentration. Concentration might in turn reveal comparative advantage, or it might reveal how the geographic distribution of demand structures depends on the distribution of other industry sectors in and outside the region. High employment or production levels will not necessarily equate to comparative advantage, but they certainly do reveal concentration and viability of the industry in the analysis region: Hence they are certainly candidates for inclusion in regional clusters. Indeed, industries with a region's highest LQ might well be the cluster anchors, those industries that form the central focus for industry clusters, often the industries that lend their names to the regional cluster (e.g., the steel cluster, the biomedical cluster, the chemical manufacturing cluster, etc.)

\subsection{Diversity}

The benefits of regional industrial diversity have long been advanced. According to Chinitz (1961, p. 281), "Large areas are more diversified than small areas. Diversified areas exhibit more stability in their growth because their fortunes are not tied to the fortunes of a few industries." The first of these two assertions is consistent with Ullman and Dacey's (1960) subsequent development of the minimum requirements (MR) approach to estimating a region's economic base. Among other things, and without tying economic base models directly to I-O, the MR reflects the fact that as regions grow, whether centered on cluster anchors or not, the incomes of workers will result in higher levels of demand for service and support activities, resulting in greater diversity by definition.

Unlike the Marshallian externalities, ${ }^{5}$ both Chinitz (1961) and Jacobs (1969) considered a diversity of industries to be "a breeding ground for new ideas and innovations because diverse industry bases in the city stimulate inter-industry knowledge transfers" (Koo, 2007, p. 997). Hence, both clustering and diversity can promote knowledge spillovers: they simply arise via different mechanisms. Derochers and Sautet (2008, p. 827) reinforce the spillover benefits of diversity, "it is likely that a more diversified environment will increase the probability of combining existing skills and resources in different configurations by offering a greater number

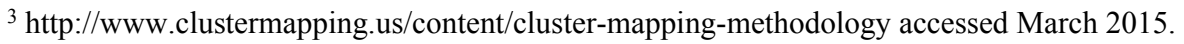

${ }^{4}$ Rocha and Sternberg (2005) use firm concentrations instead of employment concentrations to avoid cases of strong influence of big firms in the agglomeration indicator.

${ }^{5}$ Sometimes these are referred to as MAR externalities by Marshall (1980), Arrow (1962), and Romer (1986).
} 
and variety of problems to be solved, as well as a much wider pool of expert knowledge and other useful resources to develop new solutions."

Aside from the benefits of knowledge spillovers, of course, are the advantages that arise from avoiding situations in which a region's economy might be overspecialized in a single industry. Should an industry on which a large portion of a region's industry be dependent suddenly turn downward, the region's entire economy is at risk and might suffer substantially. The Cleveland and Pittsburgh steel economies are well known examples. This is the argument simplified as "not placing all of a region's employment eggs in a single industrial basket."

Other benefits to diversity can be more subtle. Chinitz (1961) identifies possible advantages of multiple small firms over large single-plant firms that might arise from areas like capital markets. Small local entrepreneurs might be more likely to invest surplus capital—e.g., start new businesses - locally than would the corporate owners of large plants. "Given an equivalent array of investment opportunities at home, the surplus capital of the multiplant industry is more likely to "leak" out to other areas" (Chinitz, 1961, p. 286-287). He adds that wage levels are often influenced by dominant industries to the disadvantage of other regional industry. These observations along with Renski's (2011, p. 490) finding that "higher industrial diversity reduces the hazard rates of new firms in five of the eight study industries" serve to suggest the broader array of motivations for regional diversification.

\subsection{Diversity measurement}

Diversity has been the primary focus of numerous studies, and has been used as one variable among sets of independent variables in more general studies, yet there have been only a small number of diversity measures. Several of the simpler measures have been used for comparison and largely as points of reference. These would include the ogive, where diversity corresponds to each of $N$ industries having $1 / N$ of the employment (or output, or income, depending on data availability), and the squared or absolute deviation from national average industrial shares. The rationale for the national average measures is that - at least in developed economies - national economies are themselves considered to be diverse. Other proxies include the industry mix component of shift-share analysis, which also implicitly reflects the norm of the national industry distribution. Some studies have also used the percent of employment in durable goods manufacturing as a proxy for a region's reliance on export income, though the direct relationship to diversity is less clear here given that durable goods manufacturing in a region might itself be specialized or diversified. ${ }^{6}$

Among the more intriguing approaches to measuring diversity-and guiding diversification - is the portfolio variance (PV) measure adapted from the finance literature (Conroy, 1972, 1974, 1975; Barth, Kraft, and Wiest, 1975; Jackson, 1984; Siegel, Alwang, and Johnson, 1994; Sherwood-Call, 1990; inter alios). With this measure, industrial concentrations of employment are seen as the region's portfolio of assets and the PV measure "reflects the structural composition of the region's economy in terms of intra- and intersectoral employment covariation. ... The measure represents a departure from normative measures by accounting for intraregional intersectoral employment relationships which may be related to factor

\footnotetext{
${ }^{6}$ See Jackson (1984) for a more comprehensive discussion of these diversity measures and of the various issues that accompany choice of measure in application.
} 
endowments" (Jackson, 1984, p. 105). In this way, it avoids the "mistake of pursuing a one-sizefits-all solution" against which Koo (2007, p. 1008) would later caution.

Two diversity measures that seem to have found widespread acceptance in the regional science and economics literature are based on entropy (Wasylenko and Erickson, 1978; Kort, 1981; Trendle, 2006; Bishop, 2008) and the Herfindahl-Hirschman Index (Diamond and Simon, 1980; Simon, 1988; Malizia and Ke, 1993; Izraeli and Murphy, 2003; Lall and Chakravorty, 2005; Mizuno, Mizutani, and Nakayama, 2006; Chiang, 2009; Fu, Dong, and Chai, 2010). To me, this seems somewhat surprising, since both are essentially naïve measures of dispersion, and are divorced conceptually from any notions of regional comparative advantage, geographically variant demand, or interindustry linkages. The norm here is essentially that of the simpler and often-dismissed ogive measure.

It would be an understatement to suggest that no consensus has developed regarding the relationship among diversity and economic performance. Wagner and Deller (1998) suggest that the principal causes of the empirical inconsistency include the use of highly aggregated data sets, theoretically poor measures of diversity, and overly simplistic statistical methods. They respond to this criticism by putting forward an I-O based "density" measure as a step toward the incorporation of interindustry linkages in diversity studies.

\section{SOME COMMENTS ON REGIONAL DYNAMICS}

In his early contributions, Chinitz (1961) asks us to think about how changes in one industry might impact its region's suitability as a location for other industries. He falls just short of identifying an interesting paradox for those who tie structure to performance too strongly. Namely, should an anchor industry in a region suffer a sharp decline, the region by most measures would as a direct consequence become more diversified, though certainly not better off. He goes on to note (p. 282) that "the region will then become more diversified in its old age, so to speak. What then? Do we correct for the increased diversification? Does it open up new opportunities to the region?"

Studies of regional industrial structure focusing on the dynamics of regional systems are increasing in number, many of which are in the context of clusters. For example, Stough (2015) has begun to focus on cluster life cycles in the context of entrepreneurship and regional economic development. Trippl and Todtling (2010) suggest that because of the life cycles of industries and regions, "old industrial regions can, in fact, be regarded as a prime example of the negative side of clustering." They identify three types of cluster renewal strategies, including "diversification into established industries that are new for the region," suggesting that this path "opens up new directions of development, broadening the economic base of the regional economy." They go on to discuss both "the emergence of clusters in established industries, that are new for the region" and cluster-based renewal based upon sectoral diversification activities of home grown firms moving into new sectors. (Trippl and Todtling, 2010, pp. 209-210).

Consistent with evolutionary reasoning, Neffke, Henning, and Boschma (2011) has observed that regional diversification emerges "as a strongly path-dependent process. Regions diversify by branching into industries that are related to their current industries." He adds that new growth paths in regions do not start from scratch but are strongly rooted in the historical

\footnotetext{
${ }^{7}$ Martin and Sunley (2003) provide a thorough critique of industry clusters along these and other lines.
} 
economic structure of a region. He also points to the loss of the entire textile and wood industry clusters in the Linköping region as an example of a situation in which "the exit of one industry can set a cascading sequence of exits into motion, leading to the departure of complete technological clusters" (Neffke, Henning, and Boschma, 2011, p. 261). In terms of dynamics, Malizia and Feser's (1999, p. 92) observations are particularly astute, "The economic diversity of a city can be defined in reference to its specializations. As additional relatively independent specializations co-locate, the area becomes more diverse. Economic diversity is the presence of multiple specializations."

\section{ANALYTICS}

With the exception of the national average measure, which implicitly assumes that all regions' industrial structures should replicate the national distribution of industry activity, and the portfolio variance diversity measure, virtually all measures of industrial diversity are standard measures of dispersion. This is true of entropy-based measures, ogive measures, and the well-known Herfindahl-Hirschman index. Although there are some theoretical justifications for the notion of diversity for diversity's sake, everything we know about location theory, historical inertia, infrastructure, localization economies, and more would suggest the ideal distribution of activity would vary by region, reflecting regional comparative advantages, historical cluster development, local comparative advantages, etc.

Indeed, and in agreement with Koo's (2007, p. 1008) assertion that "the kind of industry mix a regional economy has should be a starting point for any policy discussion on regional economic development," it would be logical to look closely at a region's existing industrial structure to identify revealed comparative advantages in order to assess potentials for development. Theoretical arguments in favor of developing industry clusters are persuasive, but so too are arguments in favor of diversifying to hedge against downturns in industries of regional over-reliance. A small region might be able to support only a single industry cluster, or perhaps no cluster at all. But as regions grow, they may be able to support not only one, but multiple clusters. A compromise solution, then, might be to follow a cluster strategy by first identifying and developing an anchor industry with revealed regional comparative advantage, then moving next to identify a second industry with regional comparative advantage in a counter-cyclical industry to serve as anchor for a second cluster. If the region is large enough, or as it continues to grow, additional clusters could be added in similar fashion. With the right tools, clustering and diversity can be reassessed periodically. An orthogonal strategy would be to identify a set of diverse regional industries with revealed comparative advantage and use those industries to identify industries whose development would best support the input requirements of the clusters they anchor.

\section{A PROPOSED METHOD}

What would be the characteristics of an analytical tool that would support the analysis of existing industry structure and could support the development of strategies for selecting new specializations into which to diversify? Such a tool would:

1. Identify distributions of industries needed to support regional structures with one or more clusters,

2. Incorporate interindustry linkages,

3. Be adaptable to specific regional industry structures, 
4. Distinguish between endogenous and exogenous demand,

5. Facilitate a comparison between existing regional structures and normative structures, and

6. Support simulations based on hypothetical industry specific expansion of the regional economy.

Where should we look for such a tool?

The natural inclination of a scientist when confronted with a new problem is to try to solve it with old tools. When he is finally convinced that the old tools will not do the job, he retreats to his shop to fashion some new tools.

-Chinitz (1961, p. 279)

Checking our old tools, then, a reasonable foundation would seem to be the I-O framework. The need to distinguish between endogenous and exogenous demand in an inputoutput system evokes the net multiplier approach of Oosterhaven and Stelder (2002). The computation of net multipliers rests on an equation system wherein $R H S$ final demands by industry are adjusted using the relationships among endogenous and exogenous demands to reflect only the exogenous portion of final demand. Net multipliers have been proposed for use in identifying the relative importance of different regional industries and are argued to be free of the double counting issues that accompany gross multipliers. However, the values of net multipliers in potential anchor sectors depend upon an already fixed economic structure. The ratios of endogenous to exogenous demand for each industry are a function of the specific regional mix of industries, irrespective of any normative structures.

A related thread of I-O research that adds extraction methods to identify key sectors and the importance of an industry or industries to a regional economy includes Temurshoev's (2010) extensions to the identification of optimal sector groupings. The identification of key sectors or critical groupings might be useful starting points, but these and related methods produce results that depend on specific current regional industrial structures and therefore relate to current realities rather than potential structures.

What we need is a cluster assessment and diversification strategy (CADS) apparatus that we can use to:

a) Select an industry or set of industries from a study region to be the anchors of one or more clusters,

b) Specify activity levels for these anchors,

c) Determine the necessary industrial distribution of supporting industries to fully support these anchors at these production levels,

d) Assess the sufficiency of the anchor industry or industries for supporting the selected clusters, and

e) Evaluate the implications of diversifying into new specializations.

Objective (a), selecting an anchor or anchors, can be achieved by any number of methods. Identifying the best approach will be left to future research. For purposes of convenience and exposition, we will simply adopt the location quotient approach, appealing to its relationship to Balassa's Index of revealed comparative advantage - recognizing, of course, that in an actual policy context a great deal more effort would be put into selecting the appropriate anchor industry or industries, and would include an assessment of historical trends 
and likely futures along with the regions' preferred development path. ${ }^{8}$ Likewise, for identifying a supporting industrial structure, the current activity level(s) in terms of employment and output will serve to establish a comprehensive distribution of supporting industries.

To identify the input requirements for supporting our anchors, we can partition the I-O accounting framework according to anchor and non-anchor industries. ${ }^{9}$ Mathematically, let

$$
\left[\begin{array}{c}
q_{r} \\
\hline q_{s}
\end{array}\right]=\left[\begin{array}{l|l}
A_{r r} & A_{r s} \\
\hline A_{s r} & A_{s s}
\end{array}\right]\left[\begin{array}{c}
q_{r} \\
\hline q_{s}
\end{array}\right]+\left[\frac{f_{r}}{f_{s}}\right]
$$

be a partitioned system where $q$ is an appropriately dimensioned outputs vector where $r$ is the set of anchor industries and $s$ is the set of support industries. The $q_{r}$ are set to the observed anchor industry output values (demand for which is revealed). $A$ is a partitioned, household endogenous matrix of direct technical coefficients and $f$ is a partitioned vector of exogenous final demands. Households are endogenous to provide for a comprehensive assessment of support industries in the spirit of economic base theory. ${ }^{10}$ The solutions for supporting sector output $q_{s}$ and constrained sector final demand are

$$
q_{s}=\left(I-A_{s s}\right)^{-1}\left(A_{s r} q_{r}+f_{s}\right) .
$$

Equation 2 includes the $f_{s}$ term for the sake of completeness, but since our solution is in search of a normative distribution where exogenous demand for non-cluster anchor sectors is zero by definition, the second RHS term reduces to $A_{s r} q_{r}$.

Because Equation 2 uses technology coefficients and not regional direct requirements coefficients, the requirements from supporting sectors are technical requirements, independent of regional structure. They represent the direct and indirect supporting sector output required to support anchor industry production. Note the solution in Equation 2 depends on the production levels of all anchor industries, which are identified by the analyst based on conditions in the region and the quantitative identification of comparative advantages. Larger regions would be expected to be able to support more and more diverse clusters, and indeed, would already have diversified into them (Malizia and Feser, 1999).

Having identified supporting sector output levels, the exogenous demand for anchor industries' outputs can be determined by the relationship in

(3) $f_{r}=\left(I-A_{r r}\right) q_{r}-A_{r s} q_{s}$

and the remainder of anchor output is required to satisfy endogenous demand of other anchors and support industries. Any negative values of $f_{r}$ would indicate that the targeted level of anchor industry output is insufficient in terms of fully satisfying system requirements.

Each industrial distribution derived from this approach provides a normative reference against which a region's actual industrial structure can be compared, satisfying methodological

\footnotetext{
${ }^{8}$ Thanks are due to Michael Lahr for suggestion on making this explicit, and also for noting that the proposed method might be best suited to assessing goods-producing industries.

${ }^{9}$ Davis and Salkin (1984) developed a parallel version of this framework to estimate the economic impacts of industry-specific supply constraints.

${ }^{10}$ A Type I model could be used, although the interpretation would now exclude the induced income production requirements.
}

(C) Southern Regional Science Association 2015. 
objectives (c) and (d). Overages reflect industries that are able to satisfy additional endogenous or exogenous demand, and deficits might form the basis for exploring import substitution possibilities subject to other location theoretic concerns. Note that industries that are ill-suited to the study region for location theoretic or other reasons can be included in the anchor industry partition, with values corresponding to region-specific supply constraints.

Objective (e), evaluating the implications of diversifying into new specializations, can be reached by treating the formulation as the basis for evaluating alternative scenarios. Future research will identify optimal approaches to identifying the number and types of diverse specializations for regions of given size, complexity, centrality, etc. Other research will relate measures based on this method to regional economic growth, stability, and development. I hope that this paper has lain a foundation for the development of what will be a wide range of future research that can support a more comprehensive understanding of the relationship between economic structure and economic performance.

\section{CONCLUSION}

In this address, I have identified a number of key dimensions of industry clusters and industrial diversification that suggest strongly that these two need not be strange bedfellows, but instead might well be very supportive partners. I developed a tool and a CADS procedure that can be used first to identify a normative distribution of industries and then to assess a region's industrial structure relative to that norm. The implications for the region of diversifying into new clusters can also be anticipated using the proposed tool. Note that the proposed method is designed to inform the planning and development process, not to strictly prescribe, and that it is geared toward assessing rather than identifying anchors.

The CADS apparatus need not be used in the context of a planned economy to be of value. Its application can identify existing strengths and gaps or bottlenecks in the regional economy - in terms of supply deficits, it can be used as a standard against which the existing distribution of industrial activity can be measured and to identify the distributional implications of diversifying into new industry clusters, all of which can lead to more rational economic development decisions.

Chinitz (1961, p. 289) wrapped up his essay in this way "I said we need new tools in regional analysis. I am prepared to modify that statement in favor of this one. We need to make better use of some old tools which we have not yet applied very extensively to regional analysis." My final message in this address is to note that in this modern era of electronic search and ease of access to the literature, it is rare that entirely new conceptual tools are developed. While it might be tempting for today's scholars to privilege recent contributions under the assumption that surely the more recent literature is state of the art, there is an abundant body of knowledge that with more or less extension and adaptation can be put to very profitable use, but all too often earlier contributions to today's solutions are overlooked. With due attention to earlier contributions, those golden nuggets can be mined and refined and prove even more valuable today than when they were first discovered.

\section{REFERENCES}

Andrews, Richard B. (1953a) "Mechanics of the Urban Economic Base: A Classification of Base Types," Land Economics, 29, 343-350. 
. (1953b) Mechanics of the Urban Economic Base: The Problem of Terminology," Land Economics, 29, 263-268.

. (1955) Mechanics of the Urban Economic Base: The Concept of Base Ratios," Land Economics, 31, 47-53.

Arrow, Kenneth J. (1962) "The Economic Implications of Learning by Doing," Review of Economic Studies, 29, 155-173.

Balassa, Bela. (1965) "Trade Liberalisation and "Revealed" Comparative Advantage," Manchester School, 33, 99-123.

Barth, James, John Kraft, and Phillip Wiest. (1975) "A Portfolio Theoretic Approach to Industrial Diversification and Regional Employment," Journal of Regional Science, 15, 9-15.

Bekele, Gashawbeza W. (2007) "Agglomeration, Spatio-economic Clustering and Competitive Performance: Methodological Approaches and Empirical Evidence from the U.S.," unpublished Ph.D. Dissertation. Morgantown, West Virginia: West Virginia University.

Bekele, Gashawbeza W. and Randall W. Jackson. (2006) “Theoretical Perspectives on Industry Clusters," Report, Regional Research Institute, West Virginia University, available online in October 2015 at http://www.rri.wvu.edu/wp-content/uploads/2012/11/bekelewp2006-5.pdf.

Beyers, William B. (1974) "On Geographical Properties of Growth Center Linkage Systems," Economic Geography, 50, 203-218.

Bishop, Paul. (2008) "Diversity and Employment Growth in Sub-regions of Great Britain," Applied Economics Letters, 15, 1105-1109.

Blumenfeld, Hans. (1955) "The Economic Base of the Metropolis: Critical Remarks on the "Basic-Nonbasic" Concept," Journal of the American Institute of Planners, 21, 114-132.

Campbell, John. (1972) "Growth Pole Theory, Digraph Analysis and Interindustry Relationships," Tijdschrift Voor Economische Social Geografie, 63, 79-87.

Chenery, Hollis B. and T. Watanabe (1958) "International Comparisons of the Structure of Production," Econometrica," 26, 487-521.

Chiang, Shu-hen. (2009) "The Effects of Industrial Diversification on Regional Unemployment in Taiwan: Is the Portfolio Theory Applicable?" Annals of Regional Science, 43, 947962.

Chinitz, Benjamin. (1961) "Contrasts in Agglomeration: New York and Pittsburgh," American Economic Review, 51, 279-289.

Conroy, Michael E. (1972) “Optimal Regional Industrial Diversification, a Portfolio-Analytic Approach," unpublished Ph.D. dissertation, University of Illinois at Urbana-Champaign.

. (1974) “Alternative Strategies for Regional Industrial Diversification," Journal of Regional Science, 14, 31-46.

. (1975) "The Concept and Measurement of Regional Industrial Diversification," Southern Economic Journal, 41, 492-505.

(C) Southern Regional Science Association 2015. 
Czamanski, Daniel Z. and Stan Czamanski. (1977) "Industrial Complexes: Their Typology Structure and Relation to Economic Development," Papers of the Regional Science Association, 38, 93-111.

Czamanski, Stan. (1971) "Some Empirical Evidence of the Strengths of Linkages between Groups of Related Industries in Urban-Regional Complexes," Papers of the Regional Science Association, 27, 137-50.

. (1973) "Linkages between Industries in Urban-Regional Complexes," Chapter 10 in George G. Judge and Takashi Takayama (eds.), Studies in Economic Planning over Space and Time. North Holland: Amsterdam, pp. 180-204.

. (1977) "Needless Complexity in Identification of Industrial Complexes Comment," Journal of Regional Science, 17, 455-457.

Czamanski, Stan and Luiz Ablas. (1979) "Identification of Industrial Clusters and Complexes: A Comparison of Methods and Findings," Urban Studies, 16, 61-80.

Darwent, David F. (1969) "Growth Poles and Growth Centers in Regional Planning-A Review," Environment and Planning, 1, 5-32.

Davis, H. Craig and E. Lawrence Salkin. (1984) "Alternative Approaches to the Estimation of Economic Impacts Resulting from Supply Constraints," Annals of Regional Science, 18, 25-34.

Delgado, Mercedes, Michael E. Porter, and Scott Stern. (2014) "Defining Clusters of Related Industries," National Bureau of Economic Research Working Paper Series, No. 20375, available online in October 2015 at http://www.nber.org/papers/w20375.

Deller, Stephen. (2012) "Targeting Industrial Gaps and Disconnects for Community Economic Development," Choices, 27(2), available online in October 2015 at http://www.choicesmagazine.org/magazine/pdf/cmsarticle_221.pdf.

Desrochers, Pierre and Frederic Sautet. (2008). "Entrepreneurial Policy: The Case of Regional Specialization vs. Spontaneous Industrial Diversity," Entrepreneurship: Theory \& Practice, 32, 813-832.

Diamond, Charles A. and Curtis J. Simon. (1990) "Industrial Specialization and the Returns to Labor," Journal of Labor Economics, 8, 175-201.

Feser, Edward J. and Edward M. Bergman. (2000) "National Industry Cluster Templates: A Framework for Applied Regional Cluster Analysis," Regional Studies, 34, 1-19.

$\mathrm{Fu}$, Shihe, Xiaofan Dong, and Guojun Chai. (2010) "Industry Specialization, Diversification, Churning, and Unemployment in Chinese Cities," China Economic Review, 21, 508-520.

Ghosh, A. and A. Chakravarti. (1970) "The Problem of Location of an Industrial Complex. In Contributions to Input-Output Analysis," in Anne P. Carter and András Bródy (eds.) Contributions to Input-Output Analysis. North-Holland: Amsterdam, pp. 164-179.

Hansen, Niles M. (1967) "Development Pole Theory in a Regional Context," Kyklos, 20, 709727.

Hirschman, Albert. (1958) The Strategy of Economic Development. Yale University Press: New Haven, CT.

(C) Southern Regional Science Association 2015. 
Isard, Walter and Eugene W. Schooler. (1959) "Industrial Complex Analysis, Agglomeration Economies, and Regional Development," Journal of Regional Science, 1, 19-33.

Isard, Walter and Thomas Vietorisz. (1955) "Industrial Complex Analysis and Regional Development," Papers in Regional Science, 1, 227-247.

Izraeli, Oded and Kevin J. Murphy. (2003) "The Effect of Industrial Diversity on State Unemployment Rate and Per Capita Income," Annals of Regional Science, 37, 1.

Jackson, Randall W. (1984) "An Evaluation of Alternative Measures of Regional Industrial Diversification," Regional Studies, 18, 103-112.

Jacobs, Jane. (1969) The Economy of Cities. Vintage: New York.

Kelton, Christina M. L., Margaret K. Pasquale, and Robert P. Rebelein. (2008) "Using the North American Industry Classification System (NAICS) to Identify National Industry Cluster Templates for Applied Regional Analysis," Regional Studies, 42, 305-321.

Koo, Jun. (2007) "Determinants of Localized Technology Spillovers: Role of Regional and Industrial Attributes," Regional Studies, 41, 995-1011.

Kort, John R. (1981) "Regional Economic Instability and Industrial Diversification in the U.S.," Land Economics, 57, 596-608.

Krugman, Paul. (1991) "Increasing Returns and Economic Geography," Journal of Political Economy, 99, 483-499.

. (1998) "What's New about the New Economic Geography?," Oxford Review of Economic Policy, 14, 7-17.

Lall, Somik V. and Sanjoy Chakravorty. (2005) "Industrial Location and Spatial Inequality: Theory and Evidence from India," Review of Development Economics, 9, 47-68.

Lasuen, Jose R. (1969) “On Growth Poles,” Urban Studies, 6, 137-161.

Leven, Charles L. (1956) "Measuring the Economic Base," Paper in Regional Science, 2, 250258.

Loviscek, Anthony L. (1982) "Industrial Cluster-analysis Backward or Forward Linkages," Annals of Regional Science, 16, 36-47.

Malizia, Emil E. and Edward J. Feser. (1999) Understanding Local Economic Development. CUPR Press/Transaction Press: Piscataway, NJ.

Malizia, Emil E. and Shanzi Ke. (1993) "The Influence of Economic Diversity on Unemployment and Stability," Journal of Regional Science, 33, 221.

Marshall, Alfred. (1890) Principles of Economics. Macmillan and Company: London.

Martin, Ron, and Peter Sunley. (2003) "Deconstructing Clusters: Chaotic Concept or Policy Panacea?," Journal of Economic Geography, 3, 5-35.

Mattila, John M. and Wilbur R. Thompson. (1955) "The Measurement of the Economic Base of the Metropolitan Area," Land Economics, 31, 215-228.

Mizuno, Keizo, Fumitoshi Mizutani, and Noriyoshi Nakayama. (2006) "Industrial Diversity and Metropolitan Unemployment Rate," The Annals of Regional Science, 40, 157- 172.

(C) Southern Regional Science Association 2015. 
Neffke, Frank, Martin Henning, and Ron Boschma. (2011) "How Do Regions Diversify Over Time? Industry Relatedness and the Development of New Growth Paths in Regions," Economic Geography, 87, 237-265.

Norcliffe, Glenn B. and Lawrence. E. Kotseff. (1980) "Local Industrial Complexes in Ontario," Annals of the Association of American Geographers, 70, 68-79.

Huallachain, Breandan O. (1984) "The Identification of Industrial-complexes," Annals of the Association of American Geographers, 74, 420-436.

Oosterhaven, Jan and Dirk Stelder. (2002) "Net Multipliers Avoid Exaggerating Impacts: With a Bi-regional Illustration for the Dutch Transportation Sector," Journal of Regional Science, 42, 533-543.

Parr, John B. (1973) “Growth Poles, Regional Development, and Central Place Theory,” Papers in Regional Science, 31, 173-212.

. (2002) "Missing Elements in the Analysis of Agglomeration Economies," International Regional Science Review, 25, 151-168.

Partridge, Mark D. (2006) "We're Right, They're Wrong, Regional Science is Where it's at," Review of Regional Studies, 36, 1-14.

. (2013) "America's Job Crisis and the Role of Regional Economic Development Policy," Review of Regional Studies, 43, 97-110.

Partridge, Mark D. and M. Rose Olfert. (2011) "The Winners' Choice: Sustainable Economic Strategies for Successful $21^{\text {st }}$-Century Regions," Applied Economic Perspectives and Policy, 33, 143-178.

Perroux, François. (1950) "Economic Space: Theory and Applications," Quarterly Journal of Economics, 64, 89-104.

Porter, Michael E. (1990) The Competitive Advantage of Nations. Simon and Shuster: New York.

. (1996). "Competitive Advantage, Agglomeration Economies, and Regional Policy," International Regional Science Review, 19, 85-90.

. (2000) "Location, Competition, and Economic Development: Local Clusters in a Global Economy," Economic Development Quarterly, 14, 15- 34.

. (2003) "The Economic Performance of Regions: Measuring the Role of Clusters," presented at The Competitiveness Institute Annual Meeting, Gothenburg, September 19.

Rasmussen, P. Nørregaard. (1957) Studies in Inter-sectoral Relations. North Holland: Amsterdam.

Reid, Neil, Bruce W. Smith, and Michael C. Carroll. (2008) "Cluster Regions: A Social Network Perspective," Economic Development Quarterly, 22, 345-352.

Renski, Henry. (2011) "External Economies of Localization, Urbanization and Industrial Diversity and New Firm Survival," Papers in Regional Science, 90, 473-502. 
Rocha, Hector O. and Rolf Sternberg. (2005) "Entrepreneurship: The Role of Clusters Theoretical Perspectives and Empirical Evidence from Germany," Small Business Economics, 24, 267-292.

Roepke, Howard, David Adams, and Robert Wiseman. (1974) "A New Approach to the Identification of Industrial Complexes Using Input-Output Data," Journal of Regional Science, 14, 15-29.

Romer, Paul M. (1986) "Increasing Returns and Long-run Growth," Journal of Political Economy, 94, 1002-1037.

Rosenfeld, Stuart A. (2001) "Backing into Clusters: Retrofitting Public Policies," unpubklished paper presented at Integration Pressures: Lessons from Around the World, a John F. Kennedy School Symposium, Harvard University, March 29-30.

Schultz, Siegfried. (1977) "Approaches to Identifying Key Sectors Empirically by Means of Input-Output Analysis," Journal of Development Studies, 14, 77-96.

Sherwood-Call, Carolyn. (1990) "Assessing Regional Economic Stability: A Portfolio Approach,” Economic Review, 1, 17-26.

Siegel, Paul B., Jeffrey Alwang, and Thomas G. Johnson. (1994) "Toward an Improved Portfolio Variance Measure of Regional Economic Stability," Review of Regional Studies, 24, 7186.

Simon, Curtis J. (1988) "Frictional Unemployment and the Role of Industrial Diversity," Quarterly Journal of Economics, 103, 715-728.

Spencer, Gregory M., Tara Vinodrai, Meric S. Gertler, and David A. Wolfe. (2010) "Do Clusters Make a Difference? Defining and Assessing their Economic Performance," Regional Studies, 44, 697-715.

Stough, Roger R. (2015) "Cluster Life-cycles, Entrepreneurship and Regional Economic Development with a Case Study of the Korean Shipbuilding Cluster," in Peter Nijkamp, Adam Z. Rose, and Karima Kourtit (eds.), Regional Science Matters. Springer Publishing: New York, pp. 223-254.

Streit, Manfred E. (1969) "Spatial Associations and Economic Linkages between Industries," Journal of Regional Science, 9, 177-188.

Temurshoev, Umed. (2010) "Identifying Optimal Sector Groupings with the Hypothetical Extraction Method," Journal of Regional Science, 50, 872-890.

Thomas, Morgan D. (1975) "Growth Pole Theory, Technological Change, and Regional Economic Growth," Papers in Regional Science, 34, 3-25.

Tiebout, Charles M. (1956) “The Urban Economic Base Reconsidered,” Land Economics, 32, 95-99.

Titze, Mirko, Matthias Brachert, and Alexander Kubis. (2011) "The Identification of Regional Industrial Clusters Using Qualitative Input-output Analysis," Regional Studies, 45, 89102.

Trendle, Bernard. (2006) "Regional Economic Instability: the Role of Industrial Diversification and Spatial Spillovers," Annals of Regional Science, 40, 767-778.

(C) Southern Regional Science Association 2015. 
Trippl, Michaela and Franz Tödtling. (2010) "Cluster Renewal in Old Industrial Regions: Continuity or Radical Change?," in Charlie Karlsson. (ed.), Handbook of Research on Cluster Theory. Edward Elgar: Cheltenham, U.K., pp. 203-218.

Ullman, Edward L. and Michael F. Dacey. (1960) "The Minimum Requirements Approach to the Urban Economic Base," Papers and Proceedings, Regional Science Association, 6, 175194.

Wagner, John E. and Steven C. Deller. (1998) "Measuring the Effects of Economic Diversity on Growth and Stability," Land Economics, 74, 541-556.

Wasylenko, Michael J. and Rodney A Erickson. (1978) “'On Measuring Economic Diversification': Comment," Land Economics, 54, 106-109.

Woodward, Douglas P. (2013) "Presidential Address: Industry Location, Economic Development Incentives, and Clusters," Review of Regional Studies, 42, 5-23.

Yu, Junbo and Randall Jackson. (2011) "Regional Innovation Clusters: A Critical Review," Growth and Change, 42, 111-124.

(C) Southern Regional Science Association 2015. 